instances of vasculitis in ankylosing spondylitis, have not been tried. Some difficulty may be expected in finding a sufficiently large number of patients for a clinical trial.

On the whole, pulmonary ventilation is remarkably well maintained by the diaphragm when ankylosing spondylitis causes a rigid chest wall and is compatible with a normal if somewhat restricted daily routine. Attacks of acute bronchitis and pneumonia are usually well tolerated. Progessive fibrosis of the upper lobes, however, is inevitably a serious matter and one which, when recognized, might be treated with any remedy which influences the course of the associated systemic disorder.

1 Hamilton, K. A., Annals of Internal Medicine, 1949, 31, 216.

2 Campbell, A. H., and MacDonald, C. B., British Fournal of Diseases of the Chest, 1965, 59, 90.

3 Jessamine, A. G., Canadian Medical Association fournal, 1968, 98, 25.

Cohen, A. A., Natelson, E. A., and Fechner, R. E., Chest, 1971, 59, 369.

Brown, W. M. C., and Doll, R., British Medical fournal, 1965, 2, 1327.

- Zorab, P., Quarterly fournal of Medicine, 1962, 31, 267.

' Hart, F. D., Emerson, P., and Gregg, I., Annals of the Rheumatic Diseases, $1963,22,11$.

\section{Diagnostic Hazard}

Recently cases of acute kidney damage have been reported after patients have been given drugs for radiological examination of the gall bladder. Fortunately, this complication is very rare, but any hazards of purely diagnostic procedures naturally cause concern. The mechanism of such renal failure is unknown. Oral cholecystographic agents are carboxylic acids, soluble in lipid, and it has been suggested that kidney damage may be caused by a uricosuric effect (which is a property of many organic acids). In this case the sudden delivery of large amounts of urate to the distal renal tubule would lead to acute destructive nephropathy.

It has now been established that these agents do increase the renal excretion of uric acid. Studying uric acid excretion in nine patients who were undergoing oral cholecystography with a single dose of iopanoic acid (Telepaque), G. H. Mudge $^{1}$ found that the average ratio of urinary uric acid to creatinine increased by $68 \%$ in the first 24 -hour period, the rise being due to an absolute increase in the amount of urate excreted. Nevertheless, this was not a constant finding, since three of the patients did not show such an increase. A further volunteer received single and double doses -3 and $6 \mathrm{~g}-$ of ipodate (Biloptin) on consecutive evenings; urate excretion increased during the night hours, returning to normal by 7 a.m., the uricosuric effect being roughly proportional to the dose. A similar effect was found in three of four patients receiving an intravenous dose of iodipamide (Biligrafin). In the same study the uricosuric properties of the urographic agent iodopyracet (diodone) ${ }^{2}$ was confirmed, but no change in the ratio of uric acid to creatinine was found in four patients receiving diatrizoate.

Similar findings are reported by A. E. Postlethwaite and W. N. Kelley, ${ }^{3}$ who noted a consistent fall in serum urate values after iopanoic acid had been used for oral cholecystography. A detailed study of three patients with gout showed that iopanoic acid caused a twofold to tenfold increase in uric acid clearance. This began one to three hours after administration of the drug, reached a peak five to seven hours later, and persisted for three to five days. The effect was abolished by oral pyrazinamide. Ipodate was also found to be uricosuric, but in contrast to the other study iodipamide was not reported to possess this property.
Though evidently oral cholecystographic agents are potent uricosuric drugs (of about the same order as probenecid) and can cause renal damage very rarely, it does not follow that one effect produces the other. Certainly, there is no direct evidence of this. No data are available of the levels of uric acid in the blood or the urine of patients who have developed kidney damage. Moreover, though crystals have been found within the lumen and cells of renal tubules in patients who had died of acute renal failure after receiving the oral contrast medium bunamiodyl, these crystals were stated to differ in appearance and histochemical reaction from those of uric acid. ${ }^{4}$ Clearly detailed studies should be done in any patient who develops kidney damage associated with the agents. Nevertheless, attempts should be made to anticipate this complication. Oral cholecystographic agents are usually given in the evening and exert their effect during the night, a period of relative oliguria which would predispose to crystal deposition. As Mudge suggests, there would appear to be no reason why a liberal fluid intake should not be encouraged at the time the drug is taken, and reduce the risks as far as possible.

1 Mudge, G. H., New England fournal of Medicine, 1971, 284, 929

2 Bonsnes, R. W., Dill, L. V., and Dana, E. S., fournal of Clinical Investigation, 1944, 23, 776.

3 Postlethwaite, A. E., and Kelley, W. N., Arthritis and Rheumatism, $1971,14,181$

4 Setter, J. G., Maner, J. F., and Schreiner, G. E., Fournal of the American Medical Association, 1963, 184, 102.

\section{Intermittent Hormones}

The concept that hormone secretion is constant has recently been challenged. Thus the normal, smooth, 24-hour cycle of corticosteroid secretion appears to result from the summation of short episodic bursts of adrenocortical activity, ${ }^{12}$ presumably secondary to intermittent release of pituitary corticotrophin (ACTH). The high plasma concentrations of corticosteroid found in the later part of the night and the early morning are associated with a number of frequently occurring bursts of corticosteroid secretion each lasting 60 and 180 minutes, while the low levels found later in the day and during the early part of the night appear to be the result of absent or infrequent periods of activity. In all, between five and 10 peaks are seen throughout the 24 hours, and active adrenocortical secretion occupies only about six hours of the day. The corticosteroid levels found at other times are the result of the slow clearance of hormone secreted earlier. In Cushing's disease, due to excessive secretion from the pituitary of corticotrophin, though the 24-hour rhythm of secretion of corticotrophin and corticosteroid is lost, a similar pulsatile secretion of corticotrophin is seen, but the secretion is at random, more frequent, and persists throughout the 24 hours. $^{3}$

Growth hormone too is secreted intermittently. In normal persons during sleep it is secreted in irregular bursts lasting up to two hours, especially during the early hours of the night. Similar though less frequent peaks may be seen during the day. These bursts are not associated with changes in blood glucose, bodily activity, or any known stimulus to release of growth hormone, though the sleep-related peaks may coincide with the slow wave activity in the electroencephalogram seen during deep sleep.4-7 Between such bursts growth hormone is often undetectable in the plasma under resting conditions. In some diabetics it has 
been suggested that the basal levels of growth hormone may be raised and the intermittent peaks more frequent than in normal persons. ${ }^{8}$

Periodic secretion of hormone of a different kind has now been reported by R. E. Bailey ${ }^{9}$ in a patient with a slowly growing malignant bronchial carcinoid tumour of the lung which was producing corticotrophin. Apart from absent pigmentation the patient had the usual features of the ectopic ACTH syndrome-hypokalaemic alkalosis, a raised blood sugar, high corticosteroid excretion and plasma levels of corticotrophin, which were not reduced during administration of dexamethasone. The unusual feature of this case was that the release of corticotrophin by the tumour, as reflected by the plasma levels of corticotrophin and the urinary excretion of corticosteroid, appeared to fluctuate periodically. The variations in urinary 17-hydroxycorticosteroids were considerable, from normal values in the nadir of the cycles to $150 \mathrm{mg}$ per day at the peaks. Such changes could not be attributed to changes in renal or hepatic function, nor to random day-to-day fluctuations, since the changes were smooth and the length of the cycle appeared to be about 18 days. There is no obvious explanation for this strange periodic activity in an apparently autonomous malignant tumour. But it is important to note that normal adrenocortical function in a patient studied only on one occasion cannot be taken to necessarily exclude the ectopic ACTH syndrome, for that tumour could be at the nadir of its periodic secretory activity.

\footnotetext{
'Hellman, L., et al., Fournal of Clinical Endocrinology and Metabolism, 1970, 30,411 .

' Krieger, D. T., Allen, W., Rizzo, F., and Krieger, H. P., fournal of Clinical Endocrinology and Metabolism, 1971, 32, 266

Hellman, L., et al., Fournal of Clinical Endocrinology and Metabolism, 1970, 30,686 .

- Quabbe, H-J., Schilling, E., and Helge, H., Fournal of Clinical Endocrinology and Metabolism, 1966, 26, 1173

${ }^{5}$ Parker, D. C., Sassin, J. F., Mace, J. W., Gotlin, R. W., and Rossman, L. G., fournal of Clinical Endocrinology and Metabolism, 1969, 29, 871. L. G., Fournal of Clinical Endocrinology and Metabolism, 1969, 29, 871. 29, 20 .

29, 20. Metabolism, 1971, 32, 65.

Johansen, K., and Hansen, A. P., British Medical fournal, 1969, 2, 356. - Bailey, R. E., fournal of Clinical Endocrinology and Metabolism, 1971, 32,
317.
}

\section{Field Service}

Though sexual licence and drug taking have loomed large in the popular mythology of pop festivals, these alfresco congregations seem in fact to be more notable for the orderly behaviour of most people who attend them. This is partly attributable to their good sense and partly to careful medical organization, expert police supervision, and thorough preparation for the movement and transport of a large number of people. In fact it is the sanitary problems that have stood out. Nor is this particularly surprising in view of the ordinary summer climate in the British Isles. This country has considerable experience of holding festivals of one sort or another in torrential, driving rain, but when some thousands of people gather for several days in a place without permanent water supply or established drainage it is clear that bad weather can play havoc with even a well-prepared temporary site.

Such a fate overtook a pop festival held last year in the West Riding of Yorkshire. The end was a quagmire, a mass of rubbish, and financial disaster. The medical ser- vices, which coped admirably with the situation, have recently been described by S. H. Brock. ${ }^{1}$ Some 15,000 to 20,000 people attended the festival on two fields, and crowd behaviour gave rise to little concern. Dr. Brock believes that a great contribution to their orderly conduct was prompt action to suppress drug taking and the strict prevention of "protection groups." About ten arrests were made, though it was considered the problem would have been much greater but for prompt police intervention. For various reasons the provision of lavatories and the water supply did not meet the requirements that had been laid down, though the catering was satisfactory. In the unshot 16 people were removed by ambulance, about half of them suffering from the effects of "exposure." First-aid workers treated many more.

A pop festival that was luckier with the weather was described earlier this year by L. K. Levens and J. E. Durham. ${ }^{2}$ It was held near Stoke on Trent in May 1970, and 35,000 to 40,000 people attended for a weekend. Despite the fine weather the nights were very cold. The authors report that this group of people "had a natural dignity, grace, and happiness that is difficult to credit (from adverse reports) unless it is seen." By prior agreement information about drug pedlers was given to the police, who presumably removed them from the site. The medical services treated eight people for drug intoxication and two for alcoholic intoxication, referring four of them (three and one from each group) to the local hospital. Apart from that the main clinical problems were infections of various kinds, lacerations, and exhaustion. At this festival the lavatory accommodation was also found to be inadequate. To cover the event 10 doctors and 36 non-medical staff were brought together, and they proved to be just enough to work a shift system.

It is clear from these two reports that careful planning beforehand, continual liaison of services throughout the festival, experienced supervision of the crowds, and strict control of the clearing up afterwards are all needed if these festivals are not to be a risk to public health. With timely zeal, therefore, the Department of $\mathrm{Health}^{3}$ has prepared some "Public Health Guidelines for Large Pop Festivals," and they should prove helpful to lay officials in local authorities as well as to doctors called upon to attend one of these gatherings. The document favours deep trench latrines, mechanically dug, rather than chemical closets and mobile toilets, and they certainly are more easily managed. But one difficulty is that a site may not be suitable for them-because it is in a water catchment area, 1 for instance, or is too rocky. The provision of an adequate water supply, too, can pose enormous difficulties, so that preliminary consultation with the water board of the area is obviously essential.

If pop festivals are not the degraded orgies they are sometimes made out to be, nor are they quite the care-free, wandervögel, healthful communing with nature that their admirers have occasionally supposed. They are commercial ventures which can succeed financially or fail, and the people who attend them pay for their entertainment-apart from the considerable numbers of gate-crashers. A fully satisfactory public health service for the occasion should therefore be included in the cost of it.

1 Brock, S. H., Community Medicine, 1971, 126, 79

2 Levens, L. K., and Durham, J. E., British Medical fournal, 1971, $1,218$.

"Public Health Guidelines for Large Pop Festivals." Obtainable from the Department of Health and Social Security, Alexander Fleming House, Elephant and Castle, London S.E.1. 